\title{
FIT IN CLOUD SOURCING ARRANGEMENTS: AN ONTOLOGICAL PERSPECTIVE
}

\begin{abstract}
Cloud sourcing seeks to leverage the vendor's expertise to support a cost-effective, reliable platform to run a business. The standardized nature of these sourcing arrangements as well as their ecosystem structure impose a number of challenges to the decision-making at client side. In this study, we argue that, ahead other, the fit between the cloud ecosystem and the client organization is decisive. However, the concept of fit in this setting is highly complex, dynamic, and difficult to grasp, thus, tightening the need for a richer understanding of cloud ecosystems as a complex technological and organizational arrangement. Our analysis reveals dimensions of fit between a client and the cloud ecosystem and proposes a new conceptualization of the underlying IT artifact.
\end{abstract}

Keywords: cloud ecosystem, sourcing, platform, fit, ontology

\section{Introduction}

Cloud services offer cost-efficient and standardized information technology (IT) resources in an on-demand model [1-3]. They are gaining momentum in research $[4,5]$ and practice [6]. Essentially, cloud services represent a form of IT sourcing, because they seek to leverage the vendor's expertise to support a cost-effective, reliable platform to run a business [1]. Whereas conventional sourcing usually entails the delivery of a dedicated, customized infrastructure, with technologies and services tailored to a firm's unique requirements [1], cloud sourcing is usually multitenant and based on highly standardized services and functionalities available to all clients [5]. However, it is this standardization that raises important theoretical issues regarding the fit between a client and the solution received from the cloud sourcing arrangement. Institutional theory [7] suggests that cloud vendors draw upon the institutional structures of the reference organizations for which they develop the functionality of their services. Organizations in different environments (e.g., geographical or industrial settings) may develop different 
institutional structures [8]. Hence, functionality standardized for one particular institutional context may not fit organizations operating in a different institutional context.

In the on-premises setting, it could be observed that vendors, such as SAP or IBM, had built up ecosystems around their technology, which allowed independent software developers (ISVs) to leverage the extensible core codebase of a technological platform to provide add-on modules to the ecosystem, which add functionality to it. This concept, in literature often referred to as platform ecosystems [9-11], offered a rich portfolio of ISVdeveloped functionality in order to react to the clients' idiosyncratic needs [12]. Similarly, an increasing number of cloud vendors transforms their model into cloud ecosystems, e.g. force.com ${ }^{1}$. Thereby, the classical hierarchical sourcing relationship (i.e., the client hires a sourcing vendor to do specified tasks), foundation for large parts of the sourcing literature [13], changes to a market coordination (i.e., the client obtains a standardized service from one of many providers). Cloud ecosystems offer a novel opportunity to respond to the specific needs of clients in their previously highly customized sourcing arrangements.

Practitioners have brought up the importance of fit in cloud sourcing, by stating that the notion of a "useful cloud service [...] varies widely" [14] and that "one size does not fit all" [15]. From a theoretical point of view, fit in this setting is highly complex due to the ecosystem's architecture [10], governance [16], and dynamics [17]. Moreover, fit in sourcing arrangements to an ecosystem must consider both its standardized (core) functionality and several (variable) functionality-adding modules. Despite the theoretical and practical need to understand the phenomenon of fit in this setting, it has not been in the focus of research. Therefore, this study addresses the following research question:

\section{How is fit between a cloud ecosystem and a client composed?}

Fit is viable in studying the phenomenon of IT sourcing [18] and one would naturally suggest that researchers in the sourcing domain have provided profound insights into the concept. However, for the past decades, large parts of sourcing research have focused on the phenomenon of outsourcing, where fit between client and vendor naturally plays a tangential role [c.f. 13]. Previous literature on fit has mostly concentrated on pure adoption scenarios [8, e.g. 19, 20]. Most notably, previous work in the enterprise systems domain drew on an ontological view as a conceptualization of information systems (IS) $[21]$ in order to study fit $[8,20]$.

\footnotetext{
${ }^{1}$ http://www.salesforce.com/platform/overview/
} 
The purpose of this study is to advance our understanding of cloud sourcing arrangements by exploring the fit between the cloud ecosystem and the client organization. In order to cope with the complexity of fit from a theoretical perspective, a balancing act between the specific properties and the relationship structure [20] of cloud sourcing arrangements is necessary. From a research perspective, our theoretical argument is that the concept of fit in this setting is underspecified primarily because the underlying IT artifact itself has been underspecified. Therefore, we offer an ontological conceptualization of the IT artifact underlying cloud ecosystems to provide insights into the dimensions constituting fit.

The remainder of the paper is structured as follows. Section 2.1 provides a brief review on our view on cloud ecosystems and the importance of fit in the sourcing decision-making. Subsequently, section 2.2 exemplifies the complexity of examining fit between a client organization and a cloud ecosystem. In section, 2.3 we motivate an ontological perspective on cloud ecosystems and discuss how the conceptualization of a cloud ecosystem artifact may provide deeper insights into the composition of fit. Then, section 3 proposes an extension of the model proposed by Strong and Volkoff [20]. Finally, section 4 concludes our propositions as well as discusses limitations and guidance for future research.

\section{Background Literature}

\subsection{The Importance of Fit in Cloud Ecosystems Sourcing}

Among others, the phenomena of outsourcing, offshoring, and backsourcing have largely influenced the discourse on sourcing in the IS discipline [e.g. 13, 22-25]. More recently, the phenomenon of cloud services is gaining momentum in research $[1,5]$ and practice $[6,26]$. Essentially, cloud services can be seen as a form of IT sourcing, i.e. cloud sourcing (see Table 1 for a distinction of the terms and their definitions), because they seek to leverage the vendor's expertise to support a cost-effective, reliable platform to run a business [1]. Although cloud sourcing is controversially discussed [e.g. 27], its potential resides in the ability to transform organizations by cutting the overall cost of doing business, by driving innovations, and by simplifying the overall process of integrating technology into the business process [5]. 


\begin{tabular}{|c|l|l|}
\hline Concept & \multicolumn{1}{|c|}{ Definition } & \multicolumn{1}{|c|}{$\begin{array}{c}\text { Guiding } \\
\text { References }\end{array}$} \\
\hline $\begin{array}{c}\text { Cloud } \\
\text { Service }\end{array}$ & $\begin{array}{l}\text { IT resources and other procurement that exhibit } \\
\text { the properties: conversion of fixed costs to } \\
\text { variable costs, fast setup time, highly standardized } \\
\text { nature, and removal of capacity constraint. }\end{array}$ & $\begin{array}{l}\text { Chen and Wu } \\
{[1]}\end{array}$ \\
\hline $\begin{array}{c}\text { Cloud } \\
\text { Platform }\end{array}$ & $\begin{array}{l}\text { The extensible codebase of a cloud-based system } \\
\text { that provides core functionality shared by the } \\
\text { modules that interoperate with it and the interfaces } \\
\text { through which they interoperate. }\end{array}$ & $\begin{array}{l}\text { Chen and Wu } \\
\text { [1], Tiwana et } \\
\text { al. (2010) }\end{array}$ \\
\hline $\begin{array}{c}\text { Cloud } \\
\text { Ecosystem }\end{array}$ & $\begin{array}{l}\text { The entity of the cloud platform and its modules. } \\
\text { Cusumano and } \\
\text { Gawer [28], } \\
\text { Tiwana et al. } \\
\text { (2010) }\end{array}$ \\
\hline ISV & $\begin{array}{l}\text { Independent software developers (ISV) } \\
\text { contributing to the cloud ecosystem by } \\
\text { complementing it with functionality-adding } \\
\text { modules. }\end{array}$ & $\begin{array}{l}\text { Tiwana et al. } \\
\text { (2010) }\end{array}$ \\
\hline
\end{tabular}

Table 1. Definitions and Core Concepts Underlying Cloud Ecosystems.

However, the cloud imposes highly standardized sourcing arrangements between the client and the provider [5]. Originally intended to enable economies of scale at the provider side, this property raises important theoretical issues concerning the fit of these arrangements with the client's needs. Seeing through the lens of institutional theory [7], one may argue that the institutional context of clients may differ [8] and cloud services developed for one set of institutional contexts may not fit organizations operating in a different institutional context [20]. Functionality standardized for one particular institutional context may not fit organizations in a different institutional setting. Practitioners $[14,15]$ have noted that fit in cloud sourcing still plays a vital role and that "one size does not fit all" [15].

In the enterprise systems domain, IS researchers have seen a similar discussion take place $[8,20,29-32]$. There, it has been argued that enterprise systems may be designed to fit standardized rather than specific requirements, and thus are "likely to be an imperfect fit in any particular instance" [20]. Following, large vendors, such as SAP, built up platform ecosystems around their technology in order to encourage partners to develop a rich portfolio of add-on functionality [12]. A similar phenomenon can be observed in the cloud setting, where an increasing number of cloud vendors transform their model into cloud ecosystems, such as force.com. The concept of platform ecosystems has found particular attention of researchers in the IS discipline $[9,10,16]$. Platform ecosystems encompass both the (core) functionality of a cloud platform shared by the modules that interoperate with it and the interfaces through which they interoperate [10]. 
However, the ecosystem nature of cloud sourcing arrangements makes an investigation of fit much more complex. On the one hand, this is due to the ecosystem's architecture [10], governance [16], and dynamics [17]. On the other hand, a plausible examination of fit must take in account both the standardized (core) functionality as well as the varying functionality added by ISVs.

Historically, the investigation of fit between the client and the solution received from a sourcing relationship has not found particular attention, because the studied relationships largely considered the outsourcing of IT resources or business processes [13]. Outsourcing arrangements usually include the transfer of IT resources that were formerly retained in-house to a third party, that in turn leases the IT resources back to the client [24], thus implying a certain fit between the client and the obtained IT resources. Mani et al. [33] utilize the information processing view of the firm to explain performance heterogeneity across business process outsourcing arrangements by determining the fit between the design of information capabilities and information requirements of the relationship. Other studies have investigated fit in terms of alignment, to emphasize the importance of a well-organized sourcing strategy $[34,35]$. The common notion amongst this stream is that the alignment between the sourcing strategy, the strategic intent, and the business strategy is critical in achieving the sourcing goal [34].

By contrast, cloud ecosystems build on standard interfaces and functionalities that are available to all client firms, whereas conventional outsourcing usually entails the delivery of a dedicated, customized infrastructure, with technologies and services tailored to a firm's unique needs (see Figure 1). Therefore, cloud ecosystem models strive toward market-based relationships, whereas classical sourcing relationships have been characterized as hierarchical relationships [1]. Hierarchical elements of sourcing governance include authority structure, incentive systems, control mechanisms, private ordering mechanisms that bypass courts, and non-market pricing systems that enable accurate compensation for changes in task specifications [33]. These elements are usually not present in cloud sourcing arrangements. In contrast, markets collect and communicate information of the relevant facts through their pricing systems [36]. Market-oriented relationships are non-idiosyncratic, i.e. the services obtained are interchangeable [37]. A potential client is therefore free to choose between similar cloud sourcing options within the market. 


\section{A) Sourcing}

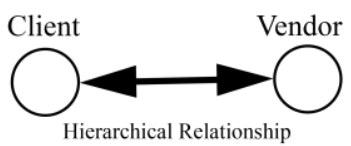

\section{B) Cloud Ecosystem Sourcing}

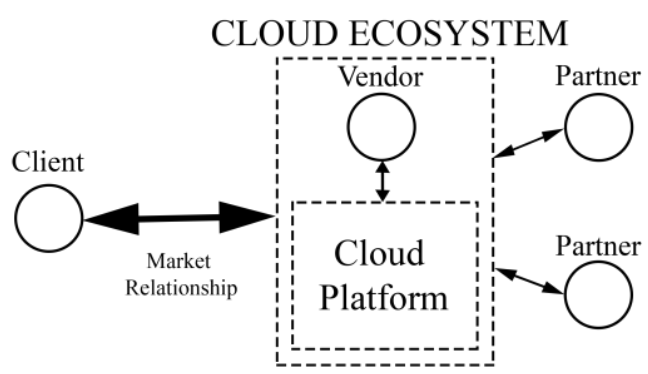

Figure 1. Sourcing (Hierarchical) and Cloud Ecosystem (Market) Arrangements.

\subsection{Understanding Fit in Cloud-Ecosystems}

The concept of fit is inherently complex and attempts have been made to structure it $[8,19,20,38]$. We regard the (1) dynamics, (2) architecture, and (3) governance of ecosystems as crucial factors for understanding the fit to the client. We argue that these ecodynamics [c.f. 17] shape the need for providing an artifactual conceptualization of the cloud ecosystem in order understand the concept of fit.

Ecosystem dynamics. In order to understand the fit in cloud sourcing, it is necessary to also consider its ecosystem structure. Growing out of the economics and management literature [16, 28, 39, 40], a burgeoning body of research has started to theorize about how ecosystems are formed and their implications for IS [10, 12, 16, 41]. Foremost, cloud ecosystems involve interactions between several actors, among others platform provider, independent software vendors (ISV), and clients [10]. A network of ISVs 
drives the development of differentiated capabilities [42]. We argue that the solution received from a cloud ecosystems is determined by the interactions of several actors [43] and dynamics [17] within the ecosystem. On the one hand, this involves a multidimensional view of fit between a platform and the client, which has not been covered by prior research. On the other hand, cloud ecosystems are therefore highly complex and different; a theoretical investigation therefore must provide an abstraction of the underlying cloud ecosystem artifact to provide insights.

Architecture. Cloud ecosystems consist of core components, i.e. the platform itself, and functionality-adding modules that are either provided by the platform provider, independent software developers in the market or the client itself [10]. Modules interoperate with the platform through standardized interfaces [42] and the entity of modules changes over time [44]. Thus, the cloud ecosystem can be structured into relatively stable part and a complementary set of modules, which extend the functionality of the platform. To best extend the functionality, the underlying cloud platforms usually build on architectures employing a high degree of modularity and decomposition [45]. We hypothesize that cloud ecosystems target a mass customization of software and may enable a feasible customization of an information system to clients with different institutional structures. The premise of modular systems theory is that a complex system consisting of smaller subsystems, which interact exclusively using predefined, stable interfaces, is more robust to change than those that are monolithic [45]. Moreover, the value of an ecosystem affiliation for any given user depends upon the modules available to the platform [12].

Ecosystem governance. Ecosystem governance deals with decisions about the vendor's relationship to its ISVs, clients, and attributes of the cloud platform. Governance must ensure robust and reconfigurable relationships between these entities in order to deal with changes inside and outside the ecosystem [46]. In particular, ensuring the ecosystem's integrity and stimulating innovation to meet idiosyncratic client needs has been suggested as crucial [10]. We hypothesize that the solution received from a cloud ecosystem is also determined by the governance of its vendor. First, governance mechanisms shape the ecosystem's relationships to its ISVs, and therefore stimulate their contribution to the ecosystem in terms of functionality-adding modules [10]. Second, governance also determines which functionality resides in the core of the platform and which functionality resides in the entity of its modules. Strategies for internalization [47], in terms of integrating modules into the core by acquisition or in-house capabilities, as well as diversification [9], in terms of mitigating dependency by letting a functionality being covered by several modules, shape the fit. 
Due to their inherent complexity and dynamics, cloud ecosystems may mislead one into overlooking the important structures and interactions within them. However, we believe that IS scholars can contribute to this discussion by opening the black box of cloud ecosystems and provide insights into the underlying IT artifact. The IT artifact itself has historically tended to disappear from view, treated as a monolithic black box, or become the omitted variable [48]. Cloud ecosystems offer the IS discipline an unusual opportunity to bring the IT artifact into the core of theory development and to contribute unique insights from an IS rather than economics or strategic perspective [10].

\subsection{Ontological Underpinnings of Cloud-sourcing Fit}

Although fit is hypothesized as only one of many decision criteria [29], it is important because potential misfits can be costly [38]. Evaluating the fit of an IS to a particular client firm has been a primary goal of practitioners and researchers in the IS field for at least two decades [e.g. 8, 49]. This has uncovered several challenges that are involved in evaluation of fit constraints.

First, the information systems part of the sourcing agreement are inherently complex; just as the real-world they intend to model [21]. This has led to underspecified conceptualizations of the IT artifact in the past [48] and borrowed theories from reference disciplines [50]. Second, fit has been characterized as a collective construct [51] and understanding its nature involves both an understanding of its parts, but also the sum of its parts and interactions in between these parts [20].

Ontology, in terms of a theory in modelling real world systems, has proven useful for cutting through this complexity $[8,52]$. For an information systems to represent a stable state, it must map the real world; hence the fit between an information system and an entity depends on how the model adequately represents the real world [21]. Comparing the representation to the ontological constructs enriches our understanding by uncovering any potentially missing or redundant constructs in the representation. Ontologies have been found to be useful in many areas, such as business systems analysis [53, 54], knowledge management, and electronic commerce [55, 56].

Bunge, Wand, and Weber's [21] propositions received particular attention by follow-up commentaries and suggestions [e.g., 20, 57]. Weber [21] distinguishes between three types of structures. Surface structure phenomena refer to facilities within the IS that allow users to interact with the IS. Deep structure phenomena are described as scripts that provide a representation of real-world systems: the things, their properties and states, and the transformations that alter those states [21]. Physical structure phenomena 
represent ways how deep and surface structures are mapped onto underlying physical technology. Latent structure phenomena are an extension proposed by Strong and Volkoff [20] and arise as secondary structures from the design of surface, deep, and physical structures. Especially, the fit between enterprise systems, in terms of highly standardized information systems, and organizations has been explored through ontological conceptualizations [8, 20]. There, it has been hypothesized that enterprise systems represent packaged, monolithic IS, which impose certain fixed physical, deep, surface, and latent structures for a client, therefore increasing the likelihood to be an imperfect fit for any adopter. The context of enterprise systems is highly related to cloud ecosystems, as they also imply standardized functionality for the client.

\section{Toward an Ontological Model of Cloud-Ecosystem Fit}

In order to conceptualize cloud ecosystem fit, we explore misfits and use them to conclude about fit [8]. Our ontological model builds on the propositions by Strong and Volkoff [20], but distinguishes two deep structures; one for capturing the ecosystem's functional core and one representing its functionality added by ISVs. In the following we will exemplify our ontological model in detail. In particular, we argue that factors in the ecosystem's dynamics, architecture, and governance shape different peculiarities of the ontological model. We see the following factors as configurational properties of a cloud ecosystem, and thus, as determinants of its output:

Openness. Openness is a crucial factor in determining the solution received from cloud ecosystems [16, 28, 43]. An ecosystem is said to be open if there are no restrictions placed on actors from joining the ecosystem [16]. Whether or not to open an ecosystem is a crucial decision for the vendor [16]. An open ecosystem has the potential to continually innovate over time, but may also reduce control and the ability to derive value [58]. Opening an ecosystem may harness network effects [58], reduce client's fear of lock-in, and stimulate functional differentiation to meet the needs of various clients [11]. Eisenmann et al. [59] distinguish between horizontal and vertical openness. First, horizontal strategies entail licensing, joint standard setting, and technological interoperability with rival platforms. Second, vertical strategies for managing openness entail backward compatibility, platform, and category exclusivity, and absorption of complements. Each of those configurations stimulates a different degree of ISVs to involve in the ecosystem and to deliver value to clients [16]. The ecosystem's output is highly contingent on these configurations, and thus, the fit between the client and the cloud ecosystem. 
Control. Control refers to formal and informal mechanisms used by a cloud ecosystem vendor to encourage or enforce desirable behaviors of the actors within the ecosystem [10]. Mechanisms to achieve control may encompass the rejection of modules from ISVs [60], internalization of ISVdeveloped modules into the core functionality of the ecosystem [47], or exclude ISVs from the ecosystem [45]. Control mechanisms ensure the vendor's flexibility and stimulate evolutionary dynamics within the ecosystem [17].

Supporting resources. Literature has recognized that ISVs may play a significant role with regards to the solution received from a cloud ecosystem $[16,61]$. It is imperative for ecosystem vendors to shift from developing applications to providing resources that support third-party developers in their development work [12]. Ecosystem vendors need to offer supporting resources, which facilitate ISVs to develop add-on modules, and thereby contributing to the platform [62]. Exemplarily, these resources may encompass development kits, trainings, consulting, and free support hotlines.

Modularity. Modularity is a continuum describing the degree to which a system's components can be separated and recombined, and it refers both to the tightness of coupling between components and the degree to which the mixing and matching of components is enabled or restricted [45]. Modularity itself is an enduring theme in IS research [e.g., 58-60]. Our understanding of modularity is grounded in Simon's [66] work, proposing that any complex organizational or technological system is composed of distinct interacting subsystems. These subsystems are to some extent interdependent and independent [67], such that a greater degree of modularity facilitates changes in particular subsystems by lowering the need for a detailed coordination of these changes [45]. Modularity of a system increases the number of possible configurations, its flexibility, and enables mass-customization [68].

Design rules. Design rules specify guidance for the development of modules by ISVs [11]. Cloud ecosystem vendors set up rules ISVs have to comply with in order to ensure interoperability with the ecosystem [42]. Design rules contribute to both stability and versatility of the ecosystem; stability ensures a common ground of assumptions for contributing ISVs, whereas versatility ensures that modules do not overly constrain each other in ways that the cloud ecosystem's flexibility and variability is reduced [10]. Thereby, design rules provide a rule-based frame for variable functionality added by ISVs. 
Decomposition. The form and function to which a cloud ecosystem is broken down into constituent subsystems represents its degree of decomposition [10]. Decomposition details which functionality is covered by the core and which functionality resides in the variable deep structure modifiable by ISVs. Decomposition minimizes interdependence among the evolution processes of components of the ecosystem, supporting change and variation, and it also helps to cope with complexity [10, 42].

Our proposed cloud ecosystem artifact maps these properties by distinguishing between core (fixed) deep structures and non-core (variable) deep structures. Core deep structures contain the basic functions, interfaces, and data of the platform artifact that are set by the vendor ex-ante and made available for implementation by ISVs. The variable deep structure contains functionality, data, and interfaces added by ISVs through complementary modules. Moreover, latent structures arise from these layers and impose cultural or process-related standards. Finally, surface structure refers to the interface of a cloud ecosystem to its client. Our model proposes that, dependent on the characteristic of the motivated factors in cloud ecosystem architecture and governance, different relationships between its actors develop and different peculiarities of the core deep, variable deep, surface, and latent structures are shaped. Based on the ontological view [21], we suggest that there are fundamentally four potential areas of misfits in cloud sourcing arrangements: core deep structure misfit, variable deep structure misfit, surface structure misfit, and latent structure misfit. Figure 2 summarizes our hypothesized IT artifact underlying cloud ecosystems and the associated misfit on each structure.

In detail, physical structures manifest in the technology used to implement the platform. In our considerations, we exclude physical structure phenomena as they inevitably underlie rapidly changing technological novelties and practices [21]. In contrast, the core deep, variable deep, surface, and latent structures of platforms are more robust compared to the underlying physical structure [20].

The core deep structures represent the unique set of functionality and data contained in a cloud platform and specifies the base ISVs build their complementary modules upon. Misfit between core deep structures and the client are crucial. They can arise if the client is forced to invest in several additional modules in order to adequately cover its business needs, because the core deep structure may cover insufficiently few functionality. 


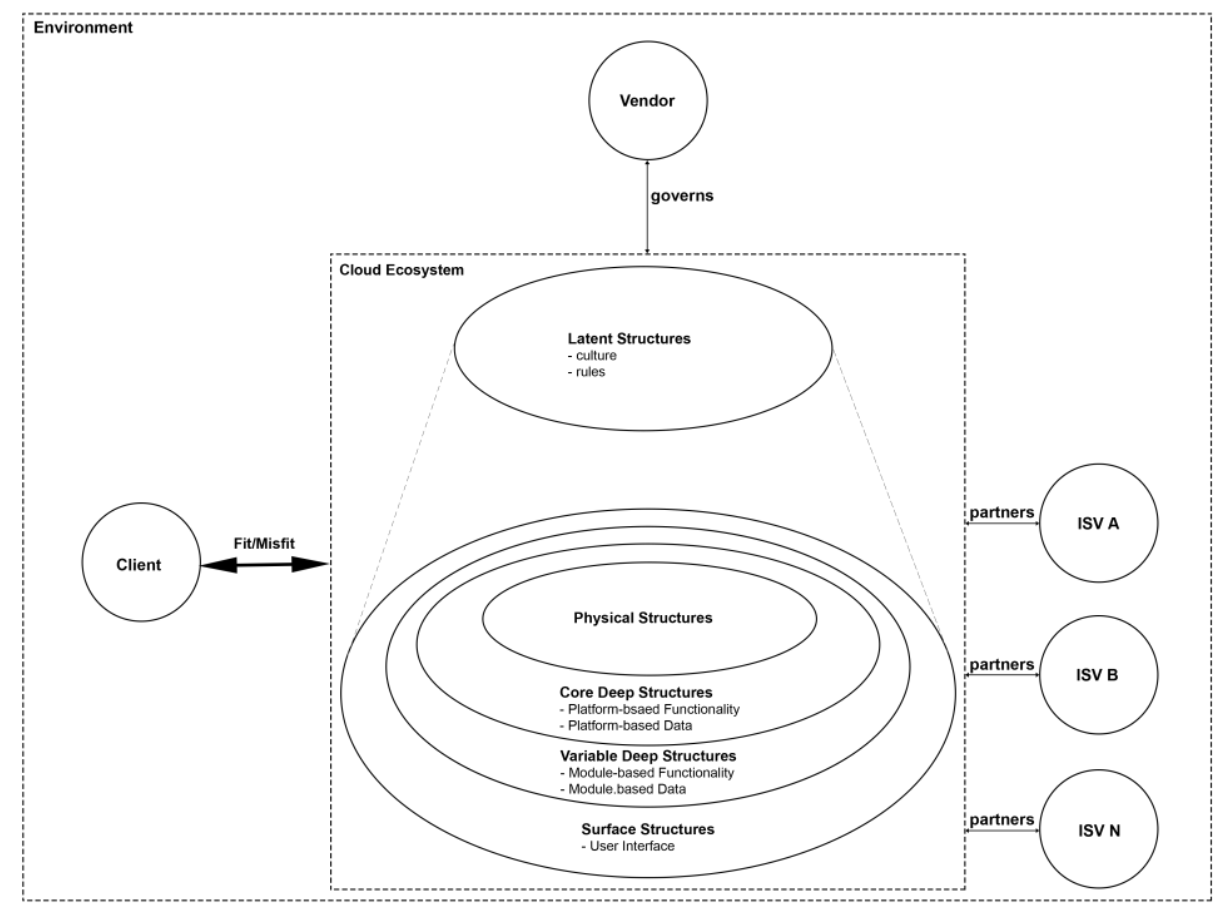

Figure 2. IT Artifact underlying Cloud-Ecosystem and the associated fits/misfits

The variable deep structure contains functionality, data, and interfaces added by ISVs through complementary modules. A platform architecture exhibiting a high degree of reusability and low variety is hypothesized to be ideal to stimulate ISVs to develop functionality-adding modules [42]. Depending on the degree of modularity, decomposition, and the design rules employed in the core, a different span [66] of the variable deep structure is possible. We hypothesize that the span of a variable deep structure is a determinant of the misfit between a cloud ecosystem and the client. A large span may reduce the likelihood of a cloud ecosystem to be an imperfect fit in any case. Governance, in terms of different decision rights, control mechanisms, and openness influences the misfit in several ways. Openness sets the boundaries for ISVs to participate in the variable deep structure in order to achieve a greater span. Decision rights partition autonomy and intellectual property among ISVs and enable the cloud ecosystem vendor to dynamically adjust certain parts of the variable deep structure. Control mechanisms may reduce the span as a whole, but allow to check for quality criteria in the variable deep structure. 
Surface structure refers to the interface of a cloud ecosystem to its client and the environment. Even though largely influenced by the core and variable deep structure, the surface structure is also independently affected by the motivated governmental and architectural factors. In concrete, criteria set in the openness rules of a cloud ecosystem detail the degree to which ISVs are allowed to extend or modify the surface structure. Exemplarily, the SAP PartnerEdge ${ }^{2}$ ecosystem does not specify mandatory guidance for the surface structure of modules created on their platform. However, extensive trainings, resources, and best practices are offered to ISVs to support them in their construction of functionality-adding modules. Moreover, a cloud ecosystem's architecture restricts or enables the design of rich surface structures by different degrees of decomposition or design rules. For example, the salesforce $^{3}$ ecosystem restricts the number of elements that can be used to create or modify the surface structure to a fixed number. Thus, misfit between the surface structure and the client may occur if a surface's interface does not support input of or access to information desired by the client.

Finally, we propose that the motivated factors also change our notion of latent structures. Governance mechanisms of informal control can foster common values, beliefs, and norms to guide module development [10]. However, misfit between latent structures and the client may arise from the way a set of physical, deep, and surface structures are designed [20]; encompassing the platform's culture, envisioned processes, and interactions. Exemplarily, research observed that SAP was historically found to impose a culture of discipline on the organization or to conflict with Asian ways of running a business $[20,30]$. We hypothesize that cloud ecosystems involve latent structure misfit, because standardized cloud sourcing arrangements naturally impose processes and culture developed for one set of, but surely not each, institutional structure.

\section{Conclusion}

The aim of our research was to provide a first conceptual discussion of how fit in cloud ecosystems is composed. We motivated this endeavor by highlighting the standardized nature of cloud ecosystem sourcing arrangements and their structure. Subsequently, we argued that the concept of fit is highly complex in cloud ecosystems. We discussed cloud ecosystem dynamics, governance, and architecture as major influences of fit in this context. Moreover, we argued that the concept of fit in cloud ecosystems is underspecified, because the underlying IT artifact itself has been

\footnotetext{
${ }^{2}$ https://www.sapappsdevelopmentpartnercenter.com/en/get-started/

${ }^{3} \mathrm{http} / / / \mathrm{www}$. salesforce.com/salesforce1/
} 
underspecified. Drawing on previous research on fit in literature on standardized information systems $[8,20]$, we employed an ontological perspective. Our model builds on the ontology proposed by Strong and Volkoff [20] and extends it by distinguishing between core and variable deep structures to map the described nature of cloud ecosystems. It has been more than a decade since Orlikowski and Lacono [48] found that most of the published studies in the IS field tended to overlook the conceptual significance of the IT artifact by using too simplistic measures, disconnecting it from social settings, black-boxing it, or even excluding it entirely. Recent reviews of the IT artifact's role propose that the field did not witness much improvement [69]. Our research was intended to shed light on the cloud ecosystem artifact in order to gain insights into the fit of cloud sourcing arrangements.

Our research is also with limitations. Foremost, our argumentation is conceptual in nature and solely drawn from a review of literature. We argue that the separation of deep structures into core and variable deep structures is crucial for understanding the fit in cloud sourcing arrangements. However, it has to be a task of future research to provide empirical evidence for our suggestions. In particular, future research may approach our propositions with the use of multiple-case studies to enrich theory on the cloud ecosystem artifact [70]. These cases should be selected with both theoretical replication and variation in mind [71].

Furthermore, ontology is useful as a theoretical foundation for modeling knowledge representation and information systems [8]. However, in the complex nature of cloud ecosystems it can only serve to model the particular output of an ecosystem, not the ecosystem itself. Other theoretical lenses, such as complex adaptive systems theory [72], may provide better mappings of the dynamics and interplay of actors inherent to ecosystems.

\section{References}

1. Chen, P., Wu, S.: The Impact and Implications of On-Demand Services on Market Structure. Information Systems Research. 24, 750-767 (2013).

2. Iyer, B., Henderson, J.: Preparing for the Future: Understanding the Seven Capabilities of Cloud Computing. MIS Quarterly Executive. 9, 117-131 (2010).

3. McAfee, A.: What Every CEO Needs to Know About the Cloud. Harvard Business Review. 89, 125-132 (2011).

4. Marston, S., Li, Z., Bandyopadhyay, S., Zhang, J., Ghalsasi, A.: Cloud Computing: The Business Perspective. Decision Support Systems. 51, 176-189 (2011). 
5. Venters, W., Whitley, E.A.: A Critical Review of Cloud Computing: Researching Desires and Realities. Journal of Information technology. 27, 179-197 (2012).

6. McKinsey: Disruptive Technologies: Advances That Will Transform Life, Business, and the Global Economy, http://www.mckinsey.com/insights/business_technology/disruptive_techn ologies.

7. DiMaggio, P.J., Powell, W.W.: The New Institutionalism in Organizational Analysis. University of Chicago Press Chicago, Chicago, USA (1991).

8. Sia, S.K., Soh, C.: An Assessment of Package-Organisation Misalignment: Institutional and Ontological Structures. European Journal of Information Systems. 16, 568-583 (2007).

9. Cusumano, M.: Technology Strategy and Management: The Evolution of Platform Thinking. Communications of the ACM. 53, 32-34 (2010).

10. Tiwana, A., Konsynski, B., Bush, A.A.: Platform Evolution: Coevolution of Platform Architecture, Governance, and Environmental Dynamics. Information Systems Research. 21, 675-687 (2010).

11. Gawer, A.: Platforms, Markets and Innovation. Edward Elgar Publishing (2011).

12. Ceccagnoli, M., Forman, C., Huang, P., Wu, D.J.: Cocreation of Value in a Platform Ecosystem: The Case of Enterprise Software. MIS Quarterly. 36, 263-290 (2012).

13. Dibbern, J., Goles, T., Hirschheim, R., Jayatilaka, B.: Information Systems Outsourcing: A Survey and Analysis of the Literature. SIGMIS Database. 35, 6-102 (2004).

14. BMC: One Size Does Not Fit All: The Case for the Custom Cloud, https://communities.bmc.com/docs/DOC-12636.

15. Ingholt, P., O'Brien, C., Bell, J.: Developing a Business Case for the Cloud, http://www.boozallen.com/media/file/developing-a-business-casefor-cloud-vp.pdf.

16. Boudreau, K.: Open Platform Strategies and Innovation: Granting Access vs. Devolving Control. Management Science. 56, 1849-1872 (2010).

17. El Sawy, O.A., Malhotra, A., YoungKi, P., Pavlou, P.A.: Seeking the Configurations of Digital Ecodynamics: It Takes Three to Tango. Information Systems Research. 21, 835-848 (2010).

18. Jae-Nam, L., Miranda, S.M., Yong-Mi, K.: IT Outsourcing Strategies: Universalistic, Contingency, and Configurational Explanations of Success. Information Systems Research. 15, 110-131 (2004).

19. Livari, J.: The Organizational Fit of Information Systems. Information Systems Journal. 2, 3-29 (1992). 
20. Strong, D.M., Volkoff, O.: Understanding Organization-Enterprise System Fit: A Path to Theorizing the Information Technology Artifact. MIS Quarterly. 34, 731-756 (2010).

21. Wand, Y., Weber, R.: On the Deep Structure of Information Systems. Information Systems Journal. 5, 203-223 (1995).

22. Lacity, M.C., Hirschheim, R.: The Information Systems Outsourcing Bandwagon. Sloan Management Review. 35, 73-86 (1993).

23. Lacity, M.C., Willcocks, L.: Global Information Technology Outsourcing: In Search of Business Advantage. John Wiley \& Sons, Inc., New York, NY, USA (2000).

24. Lacity, M.C., Willcocks, L.P.: An Empirical Investigation of Information Technology Sourcing Practices: Lessons from Experience. MIS Quarterly. 22, 363-408 (1998).

25. Lacity, M.C., Khan, S., Yan, A., Willcocks, L.P.: A Review of the IT Outsourcing Empirical Literature and Future Research Directions. J Inf technol. 25, 395-433 (2010).

26. Deloitte: Cloud Computing: Forecasting Change, https://www.deloitte.com/assets/DcomGlobal/Local\%20Assets/Documents/TMT/cloud__market_overview_and_perspective.pdf.

27. Juels, A., Oprea, A.: New Approaches to Security and Availability for Cloud Data. Communications of the ACM. 56, 64-73 (2013).

28. Cusumano, M.A., Gawer, A.: The Elements of Platform Leadership. MIT Sloan Management Review. 43, 51-58 (2002).

29. Seddon, P.B., Calvert, C., Yang, S.: A Multi-Project Model of Key Factors Affecting Organizational Benefits from Enterprise Systems. MIS Quarterly. 34, 305-340 (2010).

30. Soh, C., Kien, S.S., Tay-Yap, J.: Enterprise Resource Planning: Cultural Fits and Misfits: Is ERP a Universal Solution? Communications of the ACM. 43, 47-51 (2000).

31. Brehm, L., Heinzl, A., Markus, M.L.: Tailoring ERP Systems: A Spectrum of Choices and their Implications. HICSS (2001).

32. Nöhren, M., Heinzl, A., Kude, T.: Structural and Behavioral Fit in Software Sourcing Alignment. Proceedings of the 47th Hawaii International Conference on System Sciences (HICSS)., Waikoloa, USA (2001).

33. Mani, D., Barua, A., Whinston, A.B.: An Empirical Analysis of the Impact of Information Capabilities Design on Business Process Outsourcing Performance. MIS Quarterly. 34, 39-62 (2010).

34. Lee, J.-N.: Outsourcing Alignment with Business Strategy and Firm Performance. Communications of the Association for Information Systems. 17, 2-50 (2006). 
35. Lee, J.-N., Miranda, S.M., Kim, Y.-M.: IT Outsourcing Strategies: Universalistic, Contingency, and Configurational Explanations of Success. Information Systems Research. 15, 110-131 (2004).

36. Gurbaxani, V., Whang, S.: The Impact of Information Systems on Organizations and Markets. Communications of the ACM. 34, 59-73 (2009).

37. Dyer, J.H., Singh, H.: The Relational View: Cooperative Strategy and Sources of Interorganizational Competitive Advantage. The Academy of Management Review. 23, 660-679 (1998).

38. McLaren, T.S., Head, M.M., Yuan, Y., Chan, Y.E.: A Multilevel Model for Measuring Fit Between a Firm's Competitive Strategies and Information Systems Capabilities. MIS Quarterly. 35, 909-942 (2011).

39. Adomavicus, G., Bockstedt, J., Gupta, A., Kauffman, R.J.: Understanding Evolution in Technology Ecosystems. Communications of the ACM. 51, 117-122 (2008).

40. Katz, M.L., Shapiro, C.: Systems Competition and Network Effects. Journal of Economic Perspectives. 8, 93-115 (1994).

41. Peng, H., Ceccagnoli, M., Forman, C., Wu, D.J.: Appropriability Mechanisms and the Platform Partnership Decision: Evidence from Enterprise Software. Management Science. 59, 102-121 (2013).

42. Baldwin, C.Y., Woodard, C.J.: The Architecture of Platforms: A Unified View. Working Papers - Harvard Business School Division of Research. 1-31 (2008).

43. Eisenmann, T.R.: Managing Proprietary and Shared Platforms. California Management Review. 50, 31-53 (2008).

44. Schilling, M.A.: Technology Success and Failure in Winner-Take-All Markets: The Impact of Learning Orientation, Timing, and Network Externalities. Academy of Management Journal. 45, 387-398 (2002).

45. Schilling, M.A.: Toward a General Modular Systems Theory and Its Application to Interfirm Product Modularity. Academy of Management Review. 25, 312-334 (2000).

46. Dyer, J.H.: Effective Interfirm Collaboration: How Firms Minimize Transaction Costs and Maximize Transaction Value. Strategic Management Journal. 18, 535-556 (1997).

47. Yoffie, D.B., Kwak, M.: With Friends Like These. Harvard Business Review. 84, 88-98 (2006).

48. Orlikowski, W.J., Lacono, C.S.: Research Commentary: Desperately Seeking the "IT" in IT Research - A Call to Theorizing the IT Artifact. Information Systems Research. 12, 121-134 (2001).

49. Venkatraman, N.: The Concept of Fit in Strategy Research: Toward Verbal and Statistical Correspondence. Academy of Management Review. 14, 423-444 (1989). 
50. Grover, V., Lyytinen, K., Srinivasan, A., Tan, B.C.Y.: Contributing to Rigorous and Forward Thinking Explanatory Theory. Journal of the Association for Information Systems. 9, 40-47 (2008).

51. Morgeson, F.P., Hofmann, D.A.: The Structure and Function of Collective Constructs: Implications for Multilevel Research and Theory Development. Academy of Management Review. 24, 249-265 (1999).

52. Wynn, D., Williams, C.K.: Principles for Conducting Critical Realist Case Study Research in Information Systems. MIS Quarterly. 36, 787810 (2012).

53. Green, P., Rosemann, M.: Applying Ontologies to Business and Systems Modelling Techniques and Perspectives: Lessons Learned. Journal of Database Management. 15, 105-117 (2004).

54. Green, P.F., Rosemann, M., Indulska, M.: Ontological Evaluation of Enterprise Systems Interoperability Using ebXML. IEEE Transactions on Knowledge and Data Engineering. 17, 713-725 (2005).

55. Fensel, D.: Ontologies: Silver Bullet for Knowledge Management and Electronic Commerce. Springer-Verlag, Berlin, Heidelberg, Germany (2003).

56. Gómez-Pérez, A., Fernández-López, M., Corcho, O.: Ontological Engineering: With Examples from the Areas of Knowledge Management, e-Commerce and the Semantic Web. (Advanced Information and Knowledge Processing). Springer-Verlag New York, Inc., Secaucus, NJ, USA (2007).

57. Tegarden, D.P., Schaupp, L.C., Dull, R.B.: Identifying Ontological Modifications to the Resource-Event-Agent (REA) Enterprise Ontology Using a Bunge-Wand-Weber Ontological Evaluation. Journal of Information Systems. 27, 105-128 (2013).

58. Shapiro, C., Varian, H.: Information Rules: A Strategic Guide to the Network Economy. Harvard Business Press, Boston, MA (1999).

59. Eisenmann, T., Parker, G., Van Alstyne, M.: Platform Envelopment. Strategic Management Journal. 32, 1270-1285 (2011).

60. Cardinal, L.B.: Technological Innovation in the Pharmaceutical Industry: The Use of Organizational Control in Managing Research and Development. Organization Science. 12, 19-36 (2001).

61. Messerschmitt, D.G., Szyperski, C.: Software Ecosystem: Understanding an Indispensable Technology and Industry. MIT Press Books (2005).

62. Gawer, A., Cusumano, M.A.: Platform Leadership. Harvard Business School Press Boston (2002).

63. Banker, R.D., Datar, S.M., Kemerer, C.F., Zweig, D.: Software Complexity and Maintenance Costs. Communications of the ACM. 36, 81-94 (1993). 
64. Sanchez, R., Mahoney, J.T.: Modularity, Flexibility, and Knowledge Management in Product and Organization Design. Strategic Management Journal. 17, 63-76 (1996).

65. Susarla, A., Barua, A., Whinston, A.B.: Multitask Agency, Modular Architecture, and Task Disaggregation in SaaS. Journal of Management Information Systems. 26, 87-118 (2010).

66. Simon, H.A.: The Architecture of Complexity. Proceedings of the American Philosophical Society. 106, 467-482 (1962).

67. Tiwana, A., Konsynski, B.: Complementarities Between Organizational IT Architecture and Governance Structure. Information Systems Research. 21, 288-304 (2010).

68. Baldwin, C.Y., Clark, K.B.: Managing in an Age of Modularity. Harvard Business Review. 75, 84-93 (1997).

69. Akhlaghpour, S., Wu, J., Lapointe, L., Pinsonneault, A.: The Ongoing Quest for the IT Artifact. Journal of Information Technology. 28, 150166 (2013).

70. Yin, K.Y.: Case Study Research: Design and Methods. Sage Publications, Thousand Oaks, CA (2008).

71. Eisenhardt, K.M.: Building Theories from Case Study Research. The Academy of Management Review. 14, 532-550 (1989).

72. Holland, J.H., Miller, J.H.: Artificial Adaptive Agents in Economic Theory. The American Economic Review. 81, 365-370 (1991). 